\title{
PENGARUH PEMBERIAN TUMBUHAN AIR PADA AIR LIMBAH RUMAH TANGGA TERHADAP PERTUMBUHAN IKAN GURAMI (Osphronemus gouramy) SEBAGAI INFORMASI BAGI MASYARAKAT TENTANG PENCEMARAN LINGKUNGAN DAN DAUR ULANG LIMBAH
}

\section{Hafzon Exaputra}

\author{
SMP N 3 Batang Hari Nuban Lampung Timur
}

Email: hafzon22@yahoo.co.id

\begin{abstract}
Utilization fern (Azolla pinnata) and water hyacinth (Eichhornia crassipes) in addition to preserving the environment also produces elements that are needed for the growth of living things. Household wastewater by plants Azolla pinnata and hyacinth will return sustainability, and can be used as a maintenance gourami (Osphronemus gouramy).

The purpose of this research are: (1) to determine the effect of aquatic plants in domestic wastewater to the quality of the water quality standard household waste and growth of carp (Osphronemus gouramy). (2) to find out which one is better growth of carp (Osphronemus gouramy) in household waste water between the new and old by fern (Azolla pinnata) and by plants hyacinth (Eichhornia crassipes). (3) as a source of information for the public about environmental pollution and recycling of waste water by using plants in domestic wastewater.

This type of research experiments. Samples of each treatment 20 fish carp with 4 treatments. Treatment I (wastewater new households by ferns), treatment of II (wastewater new households by plants hyacinth), Treatment III (domestic wastewater long by ferns), treatment IV (household wastewater long by water hyacinth plants). The measured parameters ie width, length and weight of carp within a certain period. Data were analyzed using Analysis of Variance (ANOVA) two lanes and qualitative analysis.

The results obtained by analysis of existing water plants on the effect of domestic wastewater on growth of carp (Osphronemus gouramy), as well as the provision of fern (Azolla pinnata) provides the most good influence on the growth of carp.
\end{abstract}

Kata Kunci: Tumbuhan air, air limbah rumah tangga, pertumbuhan ikan gurami.

\begin{abstract}
Pemanfaatan tumbuhan paku (Azolla pinnata) dan eceng gondok(Eichhornia crassipes) selain dapat melestarikan lingkungan dan alam juga dapat menghasilkan unsurunsur yang lainnya yang sangat dibutuhkan oleh makhluk hidup untuk pertumbuhannya serta dapat memberikan keuntungan-keuntungan yang lain pula. Dengan demikian, air limbah rumah tangga yang diberi tumbuhan Azolla pinnata dan eceng gondok akan kembali kelestariannya dan dapat dipergunakan sebagai tempat pemeliharaan ikan, khususnya ikan gurami (Osphronemus gouramy) yang suka pada makanan tumbuh-tumbuhan
\end{abstract}

ini, sehingga ikan tersebut dapat tumbuh dan berkembang biak. Oleh karena itu, pada penelitian ini ingin melakukan percobaan menggunakan tumbuhan Azolla pinnata dan eceng gondok yang akan memperbaiki struktur dan kandungan air limbah rumah tangga serta akan meningkatkan produktivitas limbah itu sendiri, sehingga diharapkan air limbah rumah tangga yang telah diberi tumbuhan Azolla pinnata dan eceng gondok dapat dimanfaatkan untuk tempat pemeliharaan ikan gurami, yang juga sekaligus sebagai bahan makanan tambahan bagi ikan untuk menunjang pertumbuhan dan perkembangan hidup 
ikan tersebut. Adapun yang menjadi tujuan pada penelitian ini adalah: (1) untuk mengetahui pengaruh tumbuhan air pada air limbah rumah tangga terhadap kualitas baku mutu air limbah rumah tangga dan pertumbuhan ikan gurami (Osphronemus gouramy). (2) untuk mengetahui mana yang lebih baik pertumbuhan ikan gurami (Osphronemus gouramy) pada air limbah rumah tangga baru dan lama antara yang diberi tumbuhan paku (Azolla pinnata) dan yang diberi tumbuhan eceng gondok (Eichhornia crassipes). (3) sebagai sumber informasi bagi masyarakat tentang pencemaran lingkungan dan daur ulang limbah dengan menggunakan tumbuhan air pada air limbah rumah tangga.

\section{METODE}

Modelpenelitianyangdigunakandalam penelitianiniadalahQuasiEksperimen dengan variabel terikat pertumbuhan ikan gurami (Osphronemus gouramy), variabel bebas perlakuan pemberian tumbuhan paku (Azolla pinnata) dan eceng gondok (Eichhornia crassipes) pada air limbah rumah tangga.

Penelitian ini mengelompokkan perlakuan menjadi dua kelompok. Kelompok pertama adalah kelompok perlakuan pemberian tumbuhan paku (Azolla pinnata) dan eceng gondok (Eichhornia crassipes) pada air limbah rumah tangga baru. Kelompok keduaadalahkelompok perlakuan pemberian tumbuhan paku (Azolla pinnata) dan eceng gondok (Eichhornia crassipes) pada air limbah rumah tangga

lama. Air limbah rumah tangga yang baru adalah air limbah rumah tangga yang baru saja masuk atau mengalir ke dalam bak penampungan (kolam). Air limbah rumah tangga lama adalah air limbah rumah tangga yang telah lama berada di dalam bak penampungan (kolam), yang sudah mengalami pengendapan.

Adapun rancangan penelitian pengaruh tumbuhan paku (Azolla pinnata) dan eceng gondok (Eichhornia crassipes) pada air limbah rumah tangga terhadap pertumbuhan ikan gurami (Osphronemus gouramy) adalah:

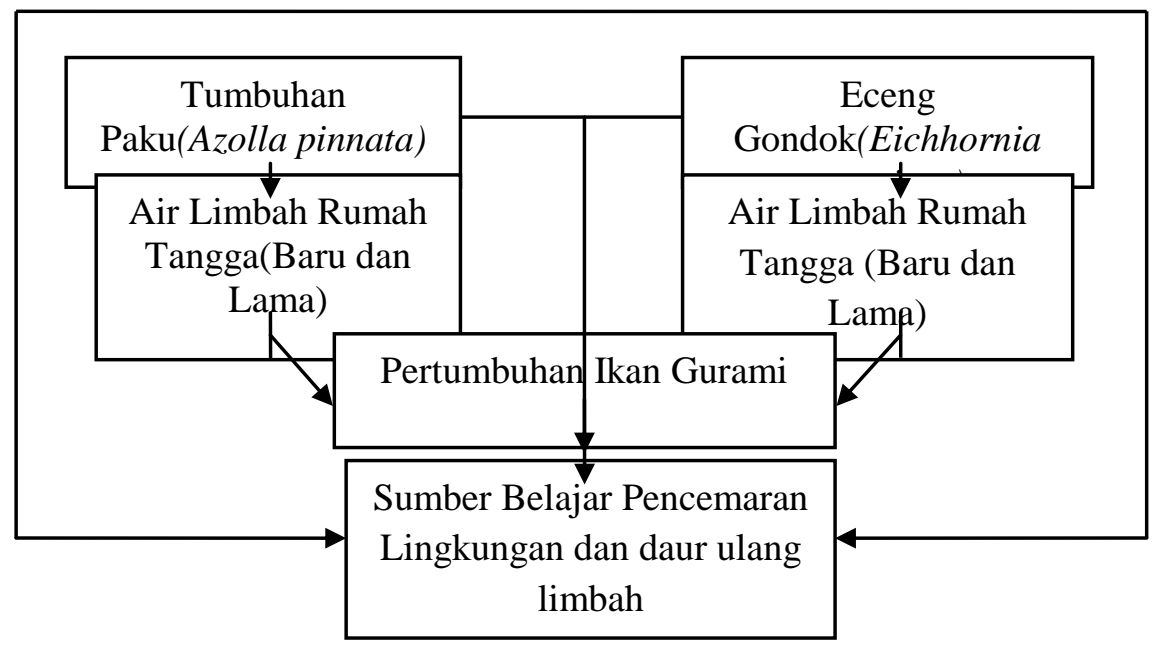

Gambar 4. Skema Rancangan Penelitian 
Langkah-langkah yang akan dilaksanakan dalam melakukan penelitian nantinya adalah:

a. Membuat kolam penelitian dengan menggunakan plastik ukuran 50 $\mathrm{cm} \times 150 \mathrm{~cm}$ dengan ke dalaman $60 \mathrm{~cm}$ sebanyak 4 kolam.

b. Selanjutnya kolam tersebut diisi dengan air limbah rumah tangga, dengan rincian 2 kolam diisi air limbah rumah tangga yang baru, dan 2 kolam lainnya diisi dengan air limbah rumah tangga yang sudah lama, yaitu yang sudah berada lama dalam kolam penampungan air limbah rumah tangga.

c. Melakukan pengukuran awal pH dan kandungan BOD serta COD air limbah rumah tangga, baik yang baru maupun yang lama.

d. kemudian, kolam tersebut diberi tumbuhan paku (Azolla pinnata) dan eceng gondok (Eichhornia crassipes) dengan luas penutupan 0,5 dari luas seluruh permukaan kolam. Hal ini didasari dari hasil penelitian yang telah dilaksanakan penulis tahun 1993, bahwa untuk pemberian tumbuhan paku pada kolam percobaan dilakukan dengan luas 0,5 bagian dari luas permukaan kolam penelitian. yang dapat dijelaskan sebagai berikut:

1. Kolam I (Air limbah rumah tangga baru): diberi tumbuhan paku(Azolla pinnata) sebanyak 0,5 luas permukaan kolam.

2. Kolam II (Air limbah rumah tangga baru): diberi tumbuhan ecenggondok (Eichhornia crassipes) sebanyak 0,5 luas permukaan kolam.

3. Kolam III (Air limbah rumah tangga lama): diberi tumbuhan paku (Azolla pinnata) sebanyak 0,5 luas permukaan kolam.
4. Kolam IV (Air limbah rumah tangga baru): diberi tumbuhan ecenggondok (Eichhornia crassipes) sebanyak 0,5 luas permukaan kolam.

e. Kolam yang telah diberi tumbuhan paku (Azolla pinnata) dan eceng gondok (Eichhornia crassipes), dibiarkan selama 7 hari. Hal ini agar tumbuhan tersebut dapat beradaptasi dahulu sehingga dapat hidup dengan baik.

f. Setelah 7 hari, langkah selanjutnya menebarkan bibit ikan gurami (Osphronemus gouramy) sebanyak 20 ekor pada masing-masing kolam penelitian. Jadi jumlah seluruh ikan gurami yang ditebar sebanyak 80 ekor. Adapun ukuran ikan gurami yang akan digunakan pada penelitian ini rata-rata lebar $4 \mathrm{~cm}$, panjang $14 \mathrm{~cm}$ dan berat $50 \mathrm{gr}$.

g. Setelah usia ikan gurami mencapai 60 hari dalam kolam penelitian, dilakukan pengukuran panjang, lebar dan berat pada semua ikan yang ditebarkan. Sebelum melakukan pengukuran pertumbuhan ikan, maka dilakukan pengukuran $\mathrm{pH}$ dan kandungan BOD serta COD air limbah rumah tangga yang telah dipakai untuk memelihara ikan tersebut.

\section{HASIL}

1. Deskripsi Data Hasil Pengukuran Lebar, Panjang dan Berat Tubuh Ikan Gurami (Osphronemus gouramy).

Berdasarkan dari hasil pengukuran berat, lebar dan panjang tubuh ikan gurami (Osphronemus gouramy), dapat dideskripsikan pada gambar 1 . 


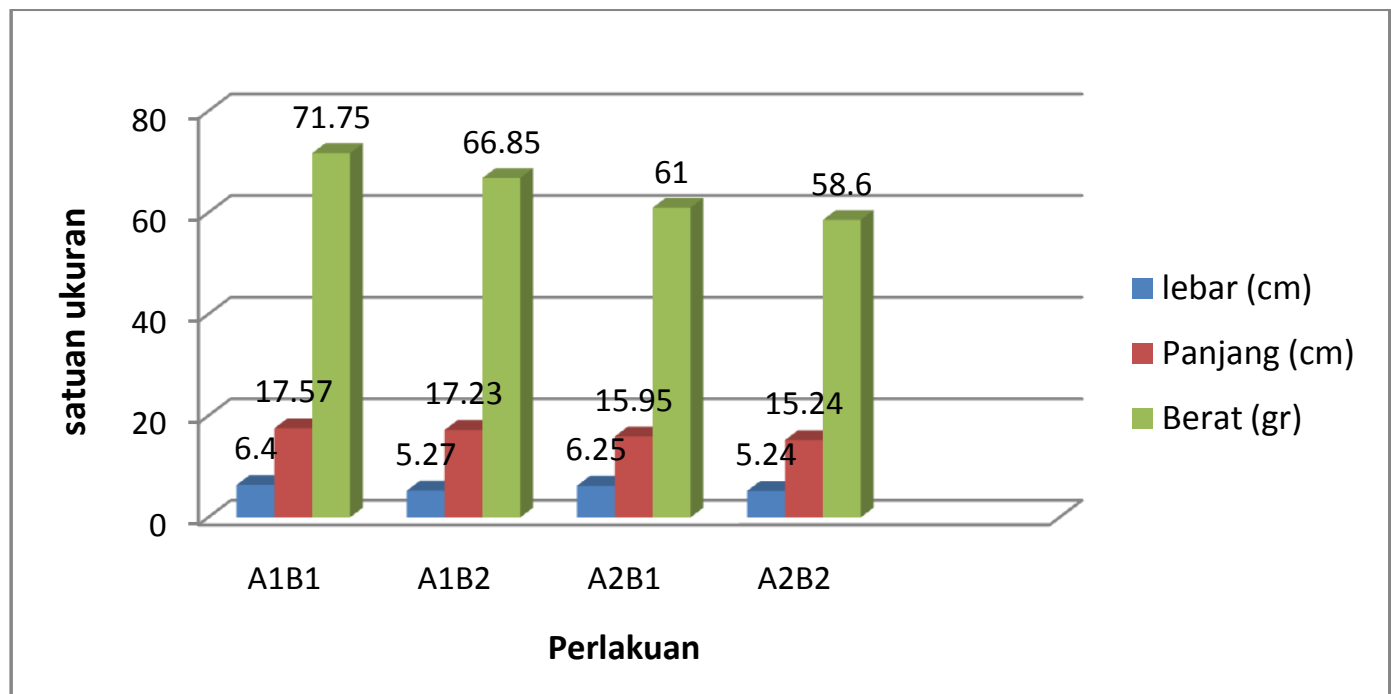

Gambar 1. Nilai rata-rata dari hasil pengukuran lebar, panjang dan berat ikan Gurami (Osphronemus gouramy)

Berdasarkan dari hasil analisis data, diperoleh rata-rata skor pertumbuhan ikan gurami, baik dari segi lebar, panjang dan berat tubuhnya pada air limbah rumah tangga yang diberi tumbuhan paku (Azolla pinnata) berbeda dengan yang diberi tumbuhan eceng gondok.

Selanjutnya pengaruhinteraksi antara jenis tumbuhan air dan air limbah rumah tangga terhadap pertumbuhan ikan gurami (Osphronemus gouramy). Dengan adanya pengaruh interaksi ini, maka baik buruknya pertumbuhan ikan gurami pada penelitian ini harus dilihat berdasarkan jenis tanaman airnya.

Dari hasil analisis data, diperoleh bahwa terdapat perbedaan yang signifikan rata-rata skor pertumbuhan ikan gurami pada air limbah rumah tangga baru antara yang diberi tumbuhan paku (Azolla pinnata) dan yang diberi tumbuhan eceng gondok. Fakta menunjukkan bahwa rata-rata skor pertumbuhan ikan gurami pada air limbah rumah tangga baru yang diberi tumbuhan paku (Azolla pinnata) lebih baik daripada rata-rata skor pertumbuhan ikan gurami pada air limbah rumah tangga baru yang diberi tumbuhan eceng gondok.

Kemudian, terdapat perbedaan yang signifikan rata-rata skor pertumbuhan ikan gurami pada air limbah rumah tangga lama antara yang diberi tumbuhan paku (Azolla pinnata) dan yang diberi tumbuhan eceng gondok. Fakta menunjukkan bahwa rata-rata skor pertumbuhan ikan gurami pada air limbah rumah tangga lama yang diberi tumbuhan paku (Azolla pinnata) lebih buruk daripada pertumbuhan lebar ikan gurami pada air limbah rumah tangga lama yang diberi tumbuhan eceng gondok.

2. Deskripsi Data Kualitas Air Limbah Rumah Tangga

Berdasarkan hasil analisis air limbah rumah tangga yang telah dilaksanakan di Politeknik Kesehatan Kementerian Kesehatan Tanjung Karang, untuk keadaan khemis air limbah rumah tangga sebelum diberi tumbuhan air diperoleh data yang dapat terlihat pada gambar 2 . 


\section{HAFZON EXAPUTRA-PERTUMBUHAN IKAN GURAME}

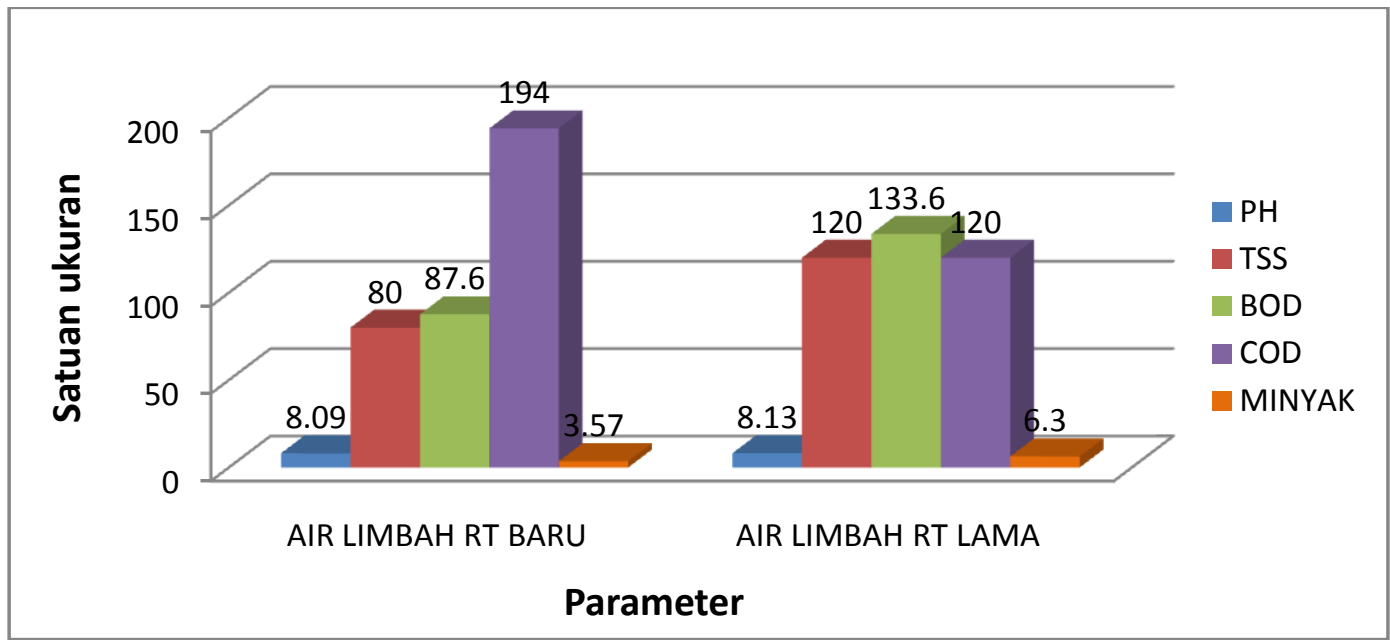

Gambar 2. Hasil Analisis Air Limbah Rumah Tangga Sebelum diberi Tumbuhan Air

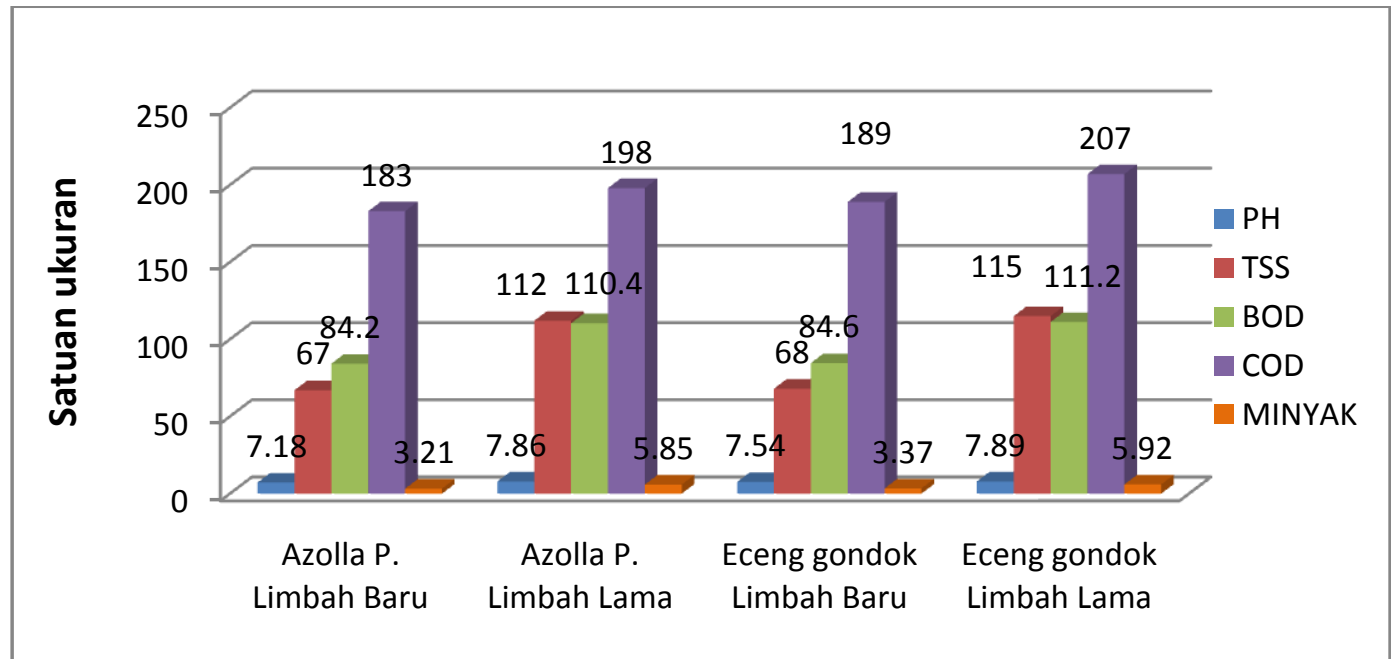

Gambar 3. Hasil Analisis Air Limbah Rumah Tangga Setelah Diberi Tumbuhan Air.

Sedangkan untuk keadaan khemis air limbah rumah tangga setelah diberi tumbuhan air berupa tumbuhan paku (Azolla pinnata) dan eceng gondok (Eichornia crassipes) dapat disajikan pada gambar 3 .

\section{PEMBAHASAN}

1. Pengaruh Tumbuhan Air Pada Air Limbah Rumah Tangga Terhadap Pertumbuhan Ikan Gurami

Pemanfaatan tumbuhan paku (Azolla pinnata) selain dapat melestarikan lingkungan dan alam, juga menghasilkan unsur-unsur yang lainnya yang sangat dibutuhkan oleh makhluk hidup untuk pertumbuhannya, serta dapat memberikan keuntungan sebagai bahan makanan bagi makhluk hidup.

Pertumbuhan ikan gurami (Osphronemus gouramy) pada air limbah rumah tangga baru dan lama yang diberi tumbuhan paku (Azolla pinnata) lebih baik daripada air limbah rumah tangga yang diberi eceng gondok karena tumbuhan paku (Azolla pinnata) memiliki kelebihan dalam 
kemampuannyabersimbiosisdenganalga hijau-biruAnabaena azollae. Tumbuhan paku ini memiliki kemampuan menyerap logam berat pada kondisi air yang tercemar. Di samping itu juga mampu merawat air yang telah terkontaminasi logam, baik logam ringan maupun berat. Dengan demikian tanamanini memilikiberbagai kelebihan di antaranya menyerap limbah cair, bahan uji ekotoksikologidan

merupakansalahsatubahanpakanternaky ang mempunyainilainutrisitinggi. Banyaknyamanfaatyangdapatdiambil daritanamanAzollapinnatainibelumdap at diberdayakan secara optimal.Tumbuhan Azolla pinnata dapat digunakan sebagai pakan ikan, pupuk organik alami dan sebagai pakan hewan lainnya.

Pemanfaatan tumbuhan paku (Azolla pinnata) dan eceng gondok(Eichhornia crassipes) selain dapat melestarikan lingkungan dan alam juga dapat menghasilkan unsurunsur yang lainnya yang sangat dibutuhkan oleh makhluk hidup untuk pertumbuhannya serta dapat memberikan keuntungan-keuntungan yang lain pula. Dengan demikian, air limbah rumah tangga yang diberi tumbuhan Azolla pinnata dan eceng gondok akan kembali kelestariannya dan dapat dipergunakan sebagai tempat pemeliharaan ikan, khususnya ikan gurami (Osphronemus gouramy) yang suka pada makanan tumbuh-tumbuhan ini, sehingga ikan tersebut dapat tumbuh dan berkembang biak.

Menurut Djojosuwito (2000) A. pinnata mempunyai kemampuan untuk menyerap logam berat sehingga dapat digunakan untuk membersihkan air dari logamberat.

Sedangkan menurut Arora (dalam Nugrahapraja:2008) bahwa Azolla, pakis air adalah calon yang ideal untuk eksploitasi di lahan basah, yang dibangun untuk merawat air limbah terkontaminasi logam.

Ecenggondokdapattumbuhdidaerahpera iranyang tercemarolehlimbah. Tumbuhanini justru mendatangkan manfaat lain, yaitu sebagai biofilter cemaran logam berat, sebagai bahan kerajinan dan campuran pakan ternak. Kandungan gizi eceng gondok ternyata juga cukup tinggi.

Secarafisiologisecenggondokdapat

berperan secara langsung dalam mengatasi

bahanpencemarperairan.Oksigen

hasilfotosintesis didaundantangkaidaun ditransfer keakaryangluassertaairdi sekitarnya.

Inimembuatrizosfermenyediakan

lingkungan mikro dengan kondisi yang kondusif bagimakhluk hidup yang berada di lokasi tersebut.Olehkarenaitu aktivitas dekomposisi oleh tumbuhan eceng gondok akan memberikan dampak yang baik bagi lingkungan perairan tercemar.

Selanjutnya Marianto (2011:69) bahwa fungsi ekologis yang dimiliki eceng gondok adalah Sebagai stabilisator suatu perairan lantaran kemampuannya menetralisir bahan pencemar yang masuk ke perairan tersebut. Lewat akarnya yang lebat, bahan pencemar itu diserap untuk digunakan dalam proses metabolismenya. Eceng gondok juga dapat menyerap kelebihan unsur hara dalam air yang dapat mengakibatkan pencemaran air berupa keluarnya bau busuk dan busa. Selain mampu mengurangi beban pencemaran bahanbahan organik, juga dapat menyerap partikel logam berat, fenol dan senyawa fosfat.

Prabaningrum (2008) menyatakan bahwahampir seluruh substansi dalam larutanpadabadanairdiserapolehakarece 
nggondok seperti layaknya spons menyerap cairan dan semua yangterkandungdida1 amnyatanpaseleks i.Peranan ecenggondokdalam menyerapberbagaiunsuradalah alasanutama pemanfaatannyasebagaidepolutanpada badanair.

Menurut Indrasti(2012) tumbuhan eceng gondokberpotensidalammenyerap logam beratkarenamerupakan tanaman dengantoleransi

tinggiyangdapattumbuh

baikdalamlimbah,pertumbuhannya

cepatserta

menyerapdanmengakumulasi

logamdenganbaik dalam waktu yang singkat.

Selanjutnya Tjitrosudirjo (dalam Prabaningrum:2008) menyatakan bahwaEcenggondokmampumenyerap timbunanlogam-logamberbahayaseperti $\mathrm{Cr}(9,4 \%), \mathrm{Cu}(29 \%), \mathrm{Zn}(26,7 \%)$, dan $\mathrm{Cd} \quad(3,92 \mathrm{mg} /(\mathrm{g}$ berat kering/hari) selama periode 14 hari Eceng gondok dapat berperan sebagaipenyerapdan penyaringlogarn-logam

berbahayaseperti

$\mathrm{Pb}(0,176 \mathrm{mg} /($ gberatkering $))$, $(0,15 \mathrm{mg} /(\mathrm{g}$ beratkering),danCdsertapestisida.

\section{Pembahasan Hasil Analisis Air Limbah Rumah Tangga}

Berdasarkan hasil analisis air limbah rumah tangga yang telah dilakukan di Laboratorium Politeknik Kesehatan Tanjung Karang pada tanggal 26 Maret 2014, bahwa antara air limbah rumah tangga baru dan lama memiliki kandungan yang berbeda. Dari data yang diperoleh ternyata kandungan air limbah rumah tangga lama lebih tinggi dari kandungan air limbah rumah tangga baru, baik dari keadaan $\mathrm{pH}$, TSS, BOD, COD maupun kandungan minyak atau lemaknya. Ini dikarenakan pada air limbah rumah tangga lama telah mengalami pengendapan dalam waktu relatif lama, sehingga kandungan-kandungan kimianya juga meningkat.

Selanjutnya, dari hasil analisis air limbah rumah tangga setelah diberi perlakuan dengan pemberian tumbuhan air, baik pada air limbah rumah tangga baru maupun pada air limbah rumah tangga lama, ternyata kandungankandungan kimianya berubah mengalami penurunan. Hal ini berarti dengan pemberian tumbuhan air pada air limbah rumah tangga dapat mengurangi beban kimia yang terkandung di dalam air limbah rumah tangga. Jika dibandingkan skor kandungan kimia antara air limbah rumah tangga yang belum diberi tumbuhan air dengan air limbah rumah tangga yang telah diberi tumbuhan air, ternyata mengalami penurunan yang signifikan.

Tujuan pengolahan air limbah adalah untuk memperbaiki kualitas air limbah, mengurangi BOD, COD dan partikel tercampur, menghilangkan bahan nutrisi dan komponen beracun, menghilangkan zat tersuspensi, mendekomposisi zat organik, menghilangkan mikroorganisme patogen (Asmadi, 2012:20).

Penggolongan air pada Pasal7 PP. No. 20 Tahun 1990 menurutperuntukkannyaditetapkanseba gaiberikut: (1). Golongan A: Airyang dapatdigunakan sebagai air minum secara langsung tanpa pengolahan terlebihdahulu.

GolonganB:Airyangdapatdigunakanse

bagaiairbakuairminum.

GolonganC:Airyangdapatdigunakanunt ukkeperluanperikanandan peternakan. (4). Golongan D: Airyang dapatdigunakan untukkeperluanpertanian, 
dandapatdimanfaatkan perkotaan,industri, listriktenagaair.

Kualitassuatuairlimbahakandapatterindi kasidarikualitas parameterkunci, dimana konsentrasi parameter kunci tidak melebihi dari standard baku mutu yang ada sesuai dengan peraturan perundang-undangan yang berlaku. Mengingat air limbah domestik kandungan terbesar adalah bahan organik, maka parameter kunci yang umum

digunakanadalahBOD,CODdanlemak/ minyak.BerdasarkanKeputusan

MenteriLingkunganHidupNomor112Ta hun 2003 tentangBakuMutu Air Limbah Domestik, maka parameterkunciuntuk airlimbahdomestikadalahBOD, TSS dan $\mathrm{pH}$ serta Lemak/Minyak.

Berdasarkan pendapat di atas, maka jelas bahwa air limbah rumah tangga yang telah diberi tumbuhan air dapat berkurang kadar COD, BOD, TSS dan $\mathrm{pH}$ serta kandungan minyak/lemaknya, sehingga dapat digunakan sebagai tempat pemeliharaan ikan gurami. Hal ini sesuai dengan standar baku mutu air untuk pemeliharaan ikan adalah kualitas air golongan $\mathrm{C}$.

\section{Sumber Informasi Masyarakat}

Di antara banyak media yang sering dipakai sebagai bahan informasi bagi masyarakat adalah media berupa brosur (leaflet) dan poster. Menurut P3KP (dalam Widowati:2010) bahwa dibandingkan bahan bacaan umum buku pengetahuan, brosur (leaflet)termasuk terbitan yang bersifat sementara, berupa lembaran dengan ukurankecil, mudah dibawa, isi tidak lengkap, mudah dipahami dan kurang teratur,sangat cocok sebagai media $\begin{array}{lrr}\text { informasi } \quad \text { yang } & \text { dapat } \\ \text { memberdayakanmasyarakat } & \text { secara }\end{array}$ aktif.

Poster adalah suatu kalimat menarik dan biasanya disertai gambar untuk menyampaikan informasi atau himbauan tertentu. Poster adalah pengumuman atau iklan berbentuk gambar atau tulisan yang ditempelkan di dinding, tembok, atau tempat-tempat umum yang strategis agar mudah diketahui banyak orang. Dalam pengertian yang lain, poster adalah ajakan atau imbauan untuk melakukan sesuatu. Jadi, sebuah poster berisi imbauan yang biasanya disertai gambar berwarna yang mudah diingat. Poster dibuat bertujuan untuk menarik perhatian banyak orang berpartisipasi memenuhi imbauan yang disampaikan dalam poster. Ukuran poster biasanya sekitar 50 x $60 \mathrm{~cm}$. Oleh karena ukurannya yang terbatas, maka tema dalam poster tidak terlalu banyak, minimal dalam satu poster hanya boleh terdapat satu tema. Tujuan poster adalah untuk mengingatkan kembali dan mengarahkan pembaca ke arah tindakan tertentu.

Dari hasil penelitian ini, penulis akan membuat brosur dan poster sebagai upaya informasi pembelajaran bagi masyarakat dalam usaha menanggulangi pencemaran lingkungan dan pemanfaatan daur ulang limbah, khususnya yang berkaitan dengan pengelolaan air limbah rumah tangga agar dapat berdaya guna bagi kesejahteraan masyarakat.

\section{KESIMPULAN DAN SARAN}

Dari hasil penelitian yang telah dilakukan, maka dapat disimpulkan: (1) terdapat pengaruh tumbuhan air pada air limbah rumah tangga terhadap kualitas baku mutu air limbah rumah 
tangga dan pertumbuhan ikan gurami (Osphronemus gouramy). pertumbuhan ikan gurami (Osphronemus gouramy) pada air limbah rumah tangga baru atau lama, yang diberi tumbuhan paku (Azolla pinnata) lebih baik daripada yang diberi tumbuhan eceng gondok (Eichhornia crassipes). (3) hasil penelitian ini dapat dijadikan sumber informasi bagi masyarakat tentang pencemaran lingkungan dan daur ulang limbah dengan menggunakan brosur dan poster. Sebagai sarannya adalah masyarakat dapat memanfaatkan air limbah rumah tangga sebagai tempat pemeliharaan ikan gurami (Osphronemus gouramy) dengan memberikan tumbuhan air, yaitu tumbuhan paku (Azolla pinnata) dan Eceng Gondok (Eichornia crassipes).

\section{DAFTAR PUSTAKA}

Asmadi dan Suharsono, 2012, DasarDasar Teknologi Pengolahan Air Limbah. Yogyakarta: Gosyen Publishing.

Djojosuwito, Soedijono, 2000, Azolla, pertanian Organik dan Multiguna, Yogyakarta: Kanisius.

Indrasti, Nastiti Siswi, dkk, 2012, Penyerapan Logam $\mathrm{Pb}$ dan $\mathrm{Cd}$ oleh Eceng Gondok: Pengaruh Konsentrasi Logam dan Lama Waktu Kontak, DepartemenTeknologiIndustriPerta nian,Fakultas

TeknologiPertanian,IPBProgram StudiPengelolaanSumberdayaAlam danLingkungan,SekolahPasca Sarjana,IPB, Vol 16(1), 44-50.

Marianto, Lukito Adi, 2001, tanaman air, Jakarta: Agro Media Pustaka

Nugrahapraja, Husna,2008, PertumbuhanTanamanAirAzolla pinnataR.Br.(MataLele)padaMedi umPertumbuhanBerbeda, skripsi tidak diterbitkan, ProgramStudiSarjanaBiologiSITH, ITB

Prabaningrum, Nunung, dkk, 2008, Daya Serap Tanaman Eceng Gondok(Eichhornia crassipesL.) Sebagai Salah Satu Alternatif Fitoremediator, Media Teknik No.4TahunXXXEdisiNopember20 08ISSN0216-3012

Widowati, Hening, 2010, Pengaruh Akumulasi Logam Berat Terhadap Proteindan Vitamin Sayuran Air Serta Pemanfaatan untuk Penyusunan Bahan Bacaan Eek Fitoremediasi, Disertasi, Tidak untuk dipublikasikan, Malang: Universitas Negeri Malang. 